\title{
Hemangiopericitoma maligno pulmonar primario/tumor fibroso solitario (HPC/TFS), con extenso compromiso endobronquial
}

\section{Malignant primary pulmonary hemangiopericytoma/ solitary fibrous tumor (HPC/SFT) with extensive endobronchial involvement}

Liliana Fernández T., MD. ${ }^{(1)}$; Luz Fernanda Sua V., MD., PhDc. ${ }^{(2)}$

${ }^{(1)}$ Medicina Interna, Neumología, Neumología intervencionista. Línea de Investigación Biomédica en Tórax. Fundación Valle del Lili. Profesora Clínica Asociada, Facultad de Ciencias de la Salud, Universidad Icesi. Cali, Colombia

${ }^{(2)}$ Anatomía Patológica y Patología Clínica, Departamento de Patología y Medicina de Laboratorio, Patología pulmonar. Ciencias Biomédicas. Línea de investigación Biomédica en Tórax, Fundación Valle del Lili. Profesora Clínica Asistente, Facultad de Ciencias de la Salud, Universidad Icesi. Cali, Colombia.

Correspondencia: Liliana Fernández $\mathrm{T}$., correos electrónicos: lfernandez@fcul.org, lilianafernandeztrujillo@gmail.com Recibido: 07/04/15, Aceptado: 28/04/15.
El HPC/TFS es una neoplasia mesenquimal rara que representa menos del $1 \%$ de los tumores vasculares. Es común en cabeza, cuello, extremidades inferiores y retro-peritoneo, así que la localización primaria en el pulmón y endobronquial es extremadamente rara.
Se trata de una paciente de 40 años con historia de disnea, dolor torácico y hemoptisis, a quien se le encontró una lesión en el HTD, con pérdida de volumen del mismo y múltiples nódulos endobronquiales evidentes en la tomografía axial computarizada (TAC) de tórax. Las

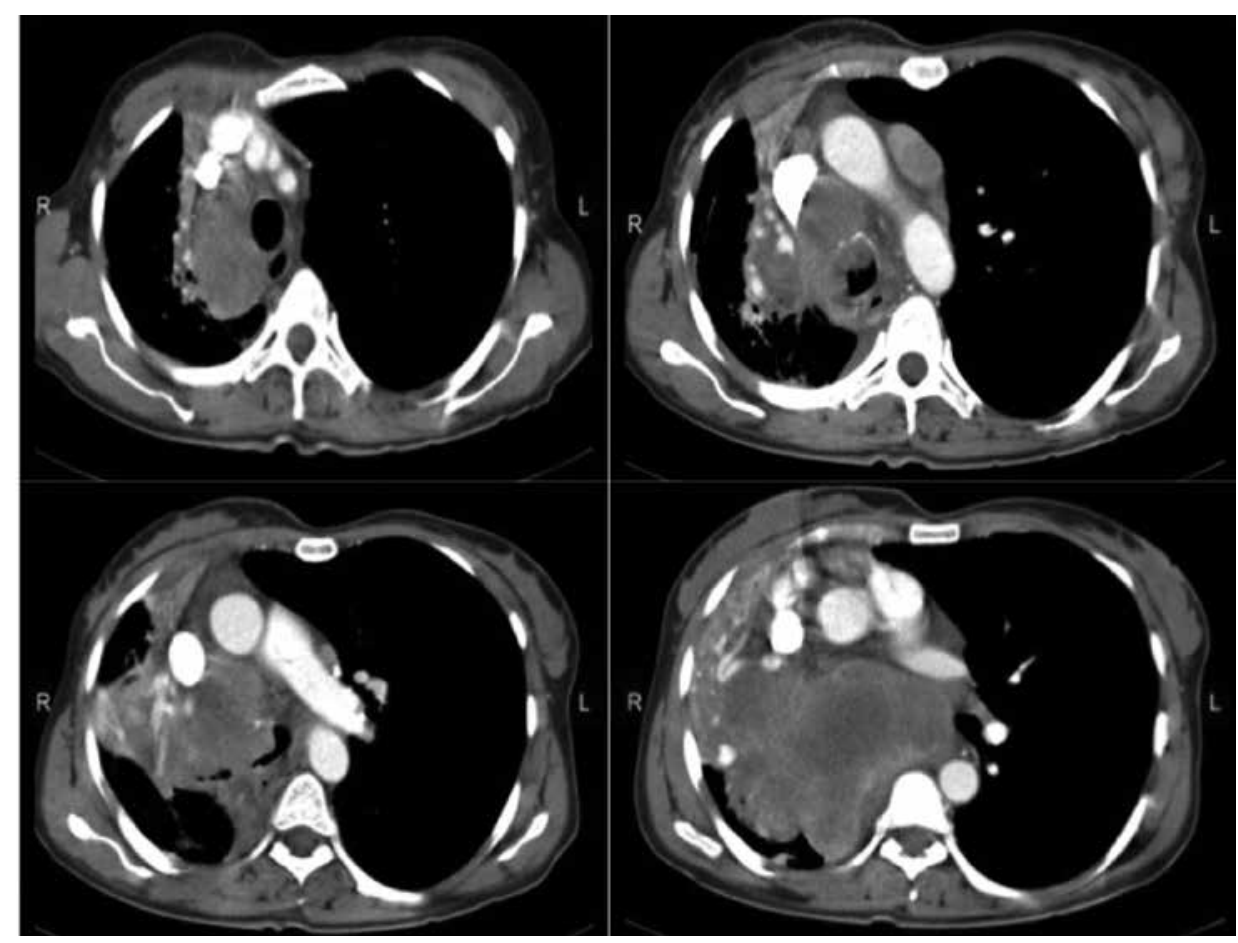

Figura 1. TAC de tórax donde se aprecia la masa que ocupa el HTD con pérdida de volumen y lesiones en la vía aérea, la tráquea y los bronquios fuentes. 

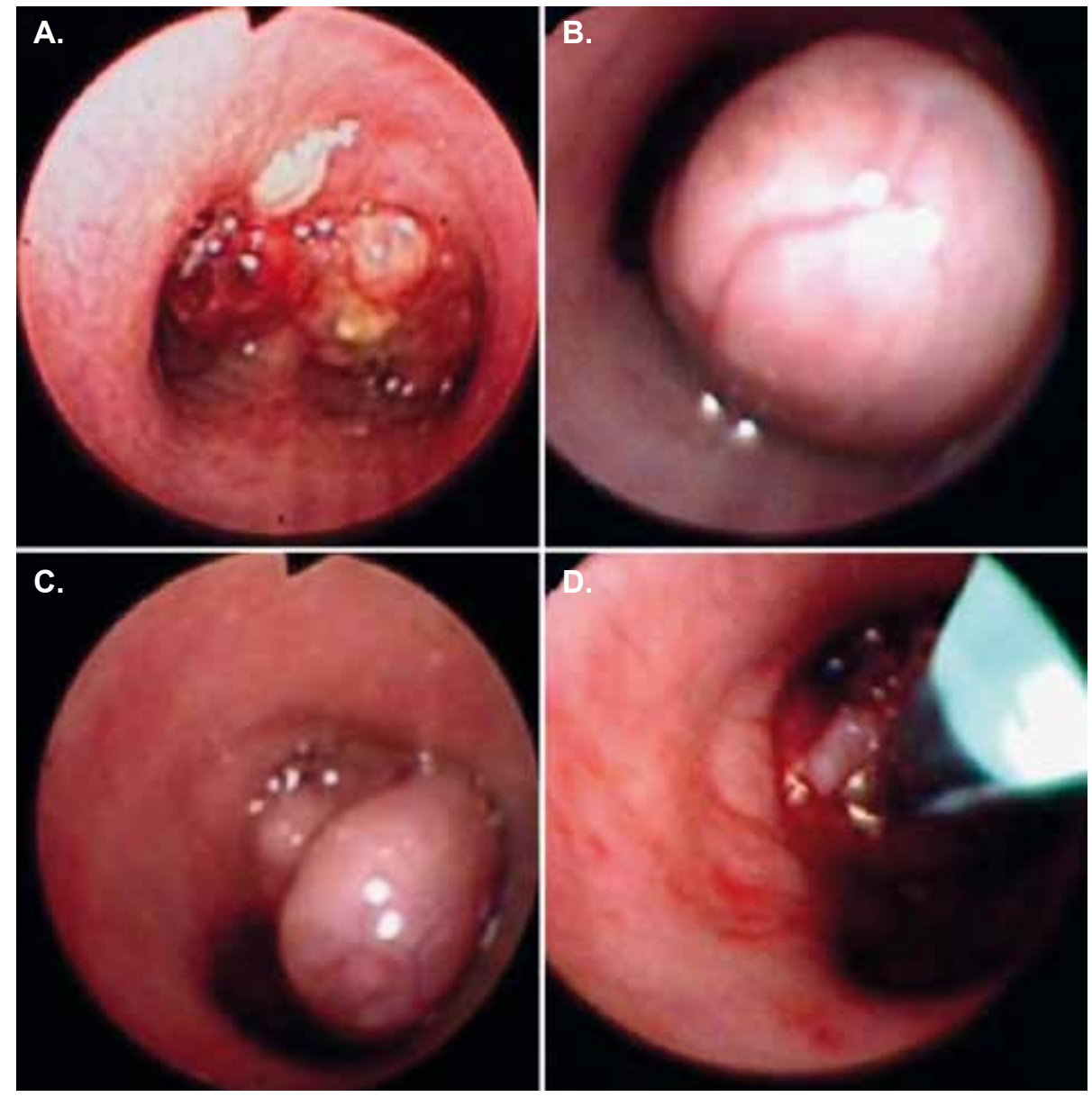

Figura 2. A. Aspecto endoscópico de la lesión en la carina obstruyendo ambos bronquios fuentes. B y C. Lesiones en la tráquea redondas brillantes pediculadas. D. Aplicación de electrocauterio para resección.

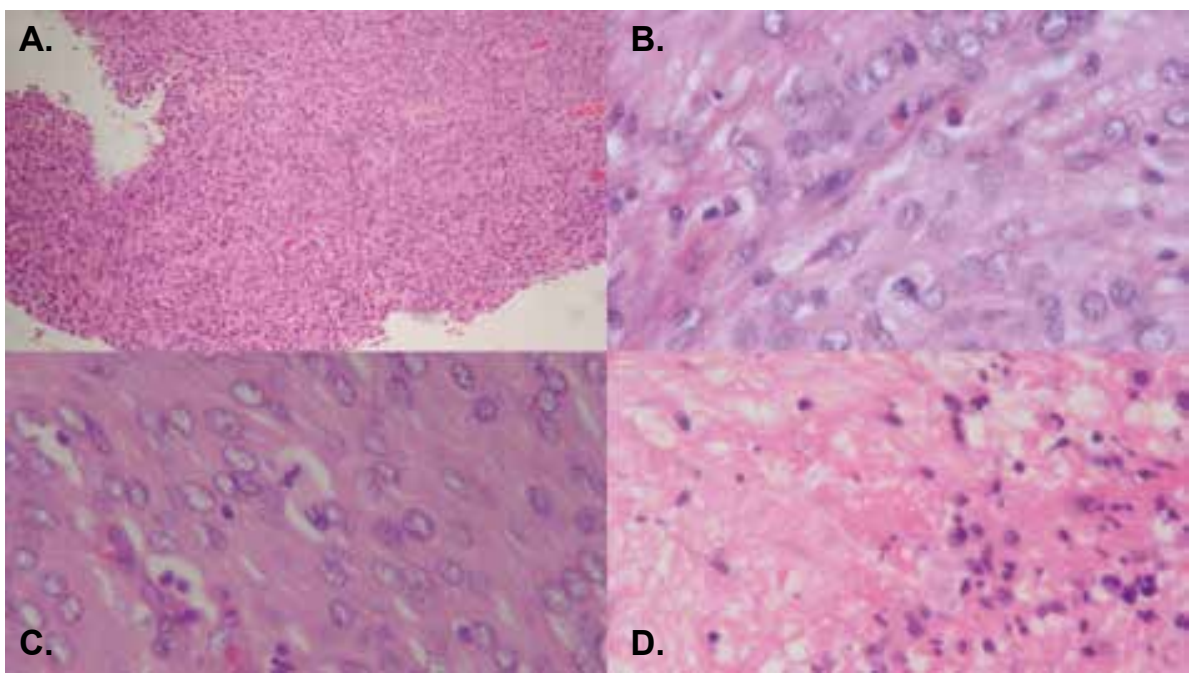

Figura 3. A, B y C. Se observa lesión de aspecto mesenquimal con células fusiformes y epitelioides, vascularizada, con canales delgados entre las células tumorales y alta actividad mitótica. D. Necrosis tumoral. Coloración hematoxilina/eosina. 
biopsias mostraron células fusiformes con gran actividad mitótica, necrosis y lesión muy vascularizada con áreas hemorrágicas. Por la magnitud y extensión de la lesión, no se consideró como candidata a cirugía. Se inició quimioterapia y un anticuerpo monoclonal bloqueador de la angiogénesis con buena respuesta al tratamiento. Desde el punto de vista endoscópico se realizó resección con electrocauterio y coagulación con argón plasma en repetidas ocasiones con permeabilización de la vía aérea y control de la hemoptisis. 